\title{
Inovando a Organização pela estratégia de Marketing Verde
}

\author{
Innovating the Organization for Green Marketing Strategy
}

\section{Azenath Alves da Silva ${ }^{1}$, Flávio de São Pedro Filho ${ }^{2}$, Janilene Vasconcelos de Melo ${ }^{2}$, Carolina Yukari Veludo Watanabe ${ }^{2}$, Marcos Cesar dos Santos ${ }^{3}$ e Ashraf Imam 4}

\begin{abstract}
Resumo: A inovação estratégica possibilita o alcance de vantagem competitiva nos negócios em um cenário dinâmico. $O$ tratamento sobre inovação nesta tarefa segue pela via do marketing verde em face do seu significado como diferencial competitivo. Para o preparo da tarefa foi tomada a Teoria da Contingência, que considera as complexidades ambientais influenciando sobre o processo de desenvolvimento de estratégias organizacionais. Levantou-se como objetivos a identificação das variáveis ambientais que influenciam na decisão em marketing verde (1), a avaliação da percepção dos atores sociais sobre as variáveis ambientais (2), e a analise da tendência no desempenho organizacional mediante a aplicação do marketing verde (3). Utilizou-se o Método do Estudo de Caso simulado, de natureza qualitativa e descritiva, com abordagem construtivista, aplicando-se procedimentos afins, com suporte do Grupo de Foco. Como resultado foram identificadas variáveis referentes à concorrência, economia, política, forças legais ou regulamentadoras, tecnológicas, socioculturais, compradores, novos entrantes, fornecedores, substitutos e concorrentes; avaliou-se a percepção por intermédio de análise e crítica dos dados obtidos dos respondentes consultados; foi analisada a tendência válida como estratégica aplicativa no marketing verde como diferencial competitivo.
\end{abstract}

Palavras-chave: Administração, Estratégia do Marketing, Organizações Dinâmicas, Sustentabilidade.

Abstract: The innovation as strategic enables the achievement of competitive advantage in business in a dynamic scenario. Treatment of innovation in this task follows the path of green marketing due of its significance as a competitive differentiator. For the preparation of the task was taken Contingency Theory, which considers the complexities environmental who influences on the process of developing organizational strategies. Have as objectives the identification of environmental factors that influence the decision on green marketing (1), the evaluation of the perception of social actors on environmental variables (2), and analysis of trend in organizational performance through the application of green marketing (3). We used the method of simulated case study, with nature qualitative and descriptive, and a constructive approach, applying procedures common for this methodology, with support from the Focus Group. As a result was identified variables related to competition, economic, political, legal or regulatory forces, technological, sociocultural, buyers, new entrants, suppliers, competitors and substitutes, is evaluated the perception through one analysis and critique of the data obtained from respondents consulted, and was analyzed the applicative of strategic as valid trend in green marketing as competitive advantage.

Keywords: Administration; Strategy the Marketing; Dynamics Organizations; Sustainability.

\footnotetext{
1 Administradora graduada pela Universidade Federal de Rondônia. Brazil. (nathy_ron@hotmail.com)

2 Professor e Pesquisador do Programa de Pós-Graduação Mestrado em Administração da Fundação Universidade Federal de Rondônia. Brazil. (flavio1954@gmail.com) (janilene18@gmail.com) (carolina@unir.br)

3 Professor do Curso de Administração da Fundação Universidade Federal de Rondônia. Brazil. (profmarcoscesar@hotmail.com)

${ }^{4}$ Is PhD in Commerce from the Aligarh Muslim University. India. (imamashraf12345@gmail.com)

Recibido: 28/04/2015; Aceptado: 04/11/2015. http://dx.doi.org/10.18004/riics.2015.diciembre.165-178
} 


\section{INTRODUÇÃO}

O crescimento intensivo do consumo e a incerteza do mercado conduzem as organizações para uma postura reagente e impulsionam tanto na administração quanto em seus colaboradores, atitudes inovadoras, principalmente na construção de estratégias. Igualmente, as novas tecnologias e a utilização intensiva dos novos recursos permitem projeção para a fidelização do consumidor de bens e serviços. Neste cenário destaca-se a importância do marketing em organizações dinâmicas, que precisam renovar suas técnicas e produtos para permanecer concorrentes ou lideres de mercado.

O Marketing Verde é usado como ferramenta para satisfazer as novas exigências do mercado consumidor. Envolve previsões sobre o meio ambiente e aspirações por fator de competitividade como vantagem sobre os concorrentes. Este estudo discorre sobre a importância e o enquadramento do Marketing Verde em organizações dinâmicas; para isso, faz uma confluência simplificada com os conceitos de inovação e suas prerrogativas, com a forma como conduzem à sustentabilidade organizacional. Focaliza ainda a estratégia como fator de competitividade na relação de responsabilidade social.

O conhecimento desenvolvido neste trabalho poderá ser aplicado em organizações que utilizam o marketing voltado para causas ambientais. Muitas organizações conhecem a importância do Marketing Verde e fazem uso desta ferramenta estratégica, porém não correspondem ao que se esperam quando o assunto pertence às relações de responsabilidade social. Muitos gestores almejam sustentabilidade, porém tratam esta ferramenta apenas como um diferencial para obter vantagem competitiva sobre a concorrência, deixando de lado as questões que envolvem amplamente essa ferramenta estratégica. O foco principal deste estudo é a inovação no processo de desenvolvimento do Marketing Verde levantando a importância desta ferramenta e qualificando-a quanto ás responsabilidades sociais que envolvem uma organização. Nesta feita, o presente instrumento monográfico pretende responder a seguinte indagação: Como as organizações dinâmicas poderiam inovar seus negócios mediante a estratégia do Marketing Verde?

As organizações necessitam envolver os consumidores na aquisição dos seus produtos, mas para que isso aconteça devem oferecer algo além do esperado; a diferenciação dos produtos; a inovação nos processos organizacionais; as novas estratégias de divulgação e até mesmo a utilização de ferramentas que envolvam o 
consumidor, em causas sociais e ambientais, está correlacionada com o sucesso da organização. Fundamentada neste pressuposto a presente pesquisa pretende desenvolver o tema Marketing Verde e levantar informações que contribuirão para organizações que estão constantemente mudando suas estratégias para alcançar seus objetivos.

A academia espera obter por meio da pesquisa os resultados para alçar o conhecimento em um campo do saber, indicado o problema a ser investigado. Cabe ao estudioso analisar os dados e aprofundar um tratamento tendo como base uma ou mais teorias e conceitos. O objetivo geral é analisar a aplicabilidade do Marketing Verde como estratégia em organizações dinâmicas; e os objetivos específicos são identificar as variáveis ambientais que influenciam na decisão em Marketing Verde (1), avaliar a percepção dos atores sociais sobre as variáveis ambientais (2), analisar a tendência no desempenho organizacional mediante a aplicação da ferramenta do Marketing Verde (3).

O mercado tende à constante mudança, seja por fator que o influencia ou que venha influenciar, ou porque as organizações necessitam de uma maior dinâmica para não serem absorvidas pelas variáveis ambientais das quais sofrem influência. Neste cenário é possivel delimitar e explorar diversos temas relevantes para enriquecer o presente trabalho. Para tanto foi realizada uma pesquisa bibliográfica com foco na Teoria da Contingência, com apropriação dos conceitos sobre Marketing, onde abrange especificamente o Marketing Verde. Traz conceitos sobre estratégia e competitividade de modo a permitir a compreensão sobre a circularidade na relação causa-efeito em uma pesquisa envolvendo a concorrência de mercado. Inovação e sustentabilidade foram manuseadas no contexto em face da sua ligação direta com o tema principal proposto, e sua importância para organizações que valorizam e sustentam suas bases sob a ótica da Responsabilidade Social, também abordada no presente instrumento.

A pesquisa bibliográfica permite afirmar que as organizações do futuro terão que possuir um diferencial científico e tecnológico avançado dentro da sua área de especialização. O Manual de Oslo (OECD, 1997) define inovação como a implementação de um produto, seja de bens de consumo ou serviços, de caráter novo ou significativamente melhorado a partir de suas características iniciais; pode ainda ser um novo processo ou método de marketing, abrangendo aqui a inovação nos negócios; neste se envolve novo modelo organizacional das práticas gerenciais, com reestruturação do local de trabalho ou das suas relações externas. Inobstante, para que o produto ou serviço seja considerado inovador, se faz fundamental a sua 
reformulação nas operações empresariais, apontando um histórico de transformação significativa e clara do diferencial entre o estágio anterior e o atual.

$\mathrm{Na}$ perspectiva da Responsabilidade Social as questões sociais e ambientais se convergem em um importante instrumento condicionador para competitividade empresarial, não importando o segmento econômico em que estão inseridas as organizações. Partindo destas variáveis sociais e ambientais, muitas empresas têm investido pesado no marketing ecológico, ou seja, o quanto antes as empresas perceberem a importância do meio ambiente, as chances de oportunidade no mercado competitivo serão maiores. Tachizawa (2006), afirma que as exigências em torno dessas variáveis exigem um posicionamento mais consistente e responsável por parte da organização, em face de sua relevância para a qualidade de vida da sociedade.

Diversas entidades se utilizam de indicadores sociais, que são informações características e operacionais das empresas para medir o grau de responsabilidade em que atuam, bem como para avaliação de clientes institucionais. Podem ser confrontados com outras empresas em processo de benchmarking, como é o caso de indicadores de desempenho global ou macroambientais; podem ser de nível setorial, como nos casos dos indicadores de qualidade, e de desempenho microambiental, do interesse entre responsáveis pela analise dos indicadores de responsabilidade social e ambiental na organização.

$\mathrm{Na}$ breve visão entre o marketing e as forças externas do ambiente, ingressa neste estudo o conceito dinâmico do marketing, pois os fatores a que ele se sujeita não são controláveis e interferem diretamente nas decisões dos departamentos organizacionais. É o que acontece quando surge uma nova lei regulamentadora de produtos, quando a economia é flutuante, quando a concorrência é inovadora, entre outras variáveis, se exige do gestor de marketing uma atualização quase instantânea, para não ficar estagnada ou aquém da concorrência. Assim, o gestor de marketing tende a se antepor às forças e fraquezas oriundas de variáveis ambientais coletando informações por meio de canais de comunicação, analisando e interpretando essas informações a fim de identificar possiveis oportunidades ou ameaças; facilita-se desta forma o planejamento, enquanto satisfaz a demanda.

$\mathrm{Na}$ Teoria Contingencial consta que a decisão depende de uma condição variável, depende da compreensão de todas as etapas atuais do ambiente de marketing. Tanto que Pride (2001) ressalta esta afirmação, sendo observadas as mudanças no ambiente, facilitando para as empresas formularem um 
planejamento estratégico; este é elaborado por decisão empresarial, como uma reação cautelosa ou proativa. Quando uma organização reage cautelosamente, significa que a variável é incontrolável e pode trazer riscos futuros; quando uma organização reage proativamente, se percebe uma reação que influencia o ambiente e tenta modificá-lo ao seu favor, criando oportunidades. As forças ambientais de marketing que oferecem oportunidade de diferenciação, concorrência e inovação são, a saber: forças concorrentes, forças econômicas, forças políticas, forças legais, forças tecnológicas e forças socioculturais.

a) Forças Concorrentes: Tem como foco principal a preferência do cliente em adquirir seus produtos, em uma mesma área geográfica.

b) Forças Econômicas: A economia tem suas oscilações, flutua conforme as circunstancias ambientais, e interfere no poder de decisão dos fornecedores e consumidores.

c) Forças Políticas: as forças politicas não agem diretamente sobre o marketing, mas influenciam as decisões, porque dependem das leis reguladoras que ditam a estrutura mercadológica.

d) Forças Legais e Reguladoras: As forças reguladoras estabelecem os limites do mercado e influenciam o marketing através da grande dimensão que exercem.

e) Forças Tecnológicas: A tecnologia parte do conhecimento individual ou coletivo, utilizando ferramentas para sanar problemas, criando mecanismos que possibilitem aos setores de uma organização, unir eficiência e eficácia, estreitando os laços da empresa com o consumidor através dos meios de comunicação.

f) Forças Socioculturais: Muitas razões socioculturais interferem nas transações comerciais. Os padrões que regem a sociedade induzem na forma como o comércio se organiza, o que uma empresa irá produzir; como irá divulgar e quais os métodos mais apropriados para a venda.

Wood Jr. (2004) teoriza que a maior dificuldade em uma organização quanto às mudanças está no fato de se construir ideias coerentes e estruturadas em um universo com grandes turbulências. A base dos negócios ambientais é uma questão de conscientização, e é por causa da falta de consciência dos consumidores e das próprias organizações que o marketing ambiental se torna estratégico como diferencial competitivo nos dias atuais. Coddington, citado por Dias (2007) faz uma apreciação sobre Marketing Ambiental como uma mudança de perspectiva, na forma de fazer negócios, porque exige responsabilidade e compromisso ambiental global da organização. Supostamente influencia nas decisões estratégicas a fim de divulgar não só o nome do produto mais proporciona proatividade para a empresa e respeito perante o consumidor. 
Já Ottman (1994) afirma que o Marketing Verde surge para "Projetar uma imagem de alta qualidade, incluindo sensibilidade ambiental, quanto aos atributos de um produto e quanto ao registro de trajetória de seu fabricante, no que se refere a respeito ambiental; para este autor o "Marketing Verde agrega valor ao produto, oferece projeções positivas, e uma boa imagem da empresa, possibilitando para os gestores de marketing o papel de inovar em um novo estilo de marketing, que é o ecológico".

\section{METODOLOGIA}

Esta é uma pesquisa exploratória, com base bibliográfica instada na probabilidade de se fazer conhecer a realidade da aplicação do Marketing Verde como ferramenta de mudança de cultura organizacional, bem como inserção das organizações no mercado pretendido. O método utilizado é o Estudo de Caso, com procedimentos comuns a este. O preparo envolveu a utilização de ferramentas de busca de informação de diversas naturezas.

Foi utilizado o meio virtual, como plataforma apta para o envolvimento dos atores sociais em Grupo de Foco referido em Cooper et al. (2004); modelagens como esta que já estão sendo construídas e aplicadas em outras instituições brasileiras, como a Universidade Federal de Minas Gerais e a Universidade de São Paulo, embora não tenham ainda publicado sobre a forma de utilização de espaços virtuais na elaboração de ambiente web para o Grupo de Foco. Assim, um site interativo permitiu a aplicação de questionários, coleta de pronunciamentos, escrutínio de resultados, aferição de respostas, graficação dos resultados e oferecimento de análise com críticas. O Grupo de Foco foi constituído de 15 a 20 individuos, previamente selecionados, entre pessoas que de alguma forma detenham conhecimento sobre o objeto em investigação; são professores de Marketing, pesquisadores da área, comerciantes, ambientalistas de reconhecido saber, agentes da mídia local e outros que possam oferecer suporte na elaboração de constructos válidos.

\section{RESULTADOS E DISCUSSÃO}

Foram identificadas as variáveis ambientais que influenciam na decisão em Marketing Verde; analisando os dados do Gráfico 1, constata-se que onze dos vinte respondentes consultados, indicam como fator que mais motiva o consumidor na hora de escolher e adquirir um produto ou serviço é a qualidade que se assimila a esses produtos. De fato, estudo em Kotler (2000) reforça este fator quando afirma 
que "os clientes estão exigindo cada vez mais qualidade e serviços superiores...". Este resultado conduz a inferência de, inobstante o consumidor especular sobre outros fatores, a qualidade é, e sempre será vista como condição primordial e amplamente influente sobre esses produtos ou serviços.

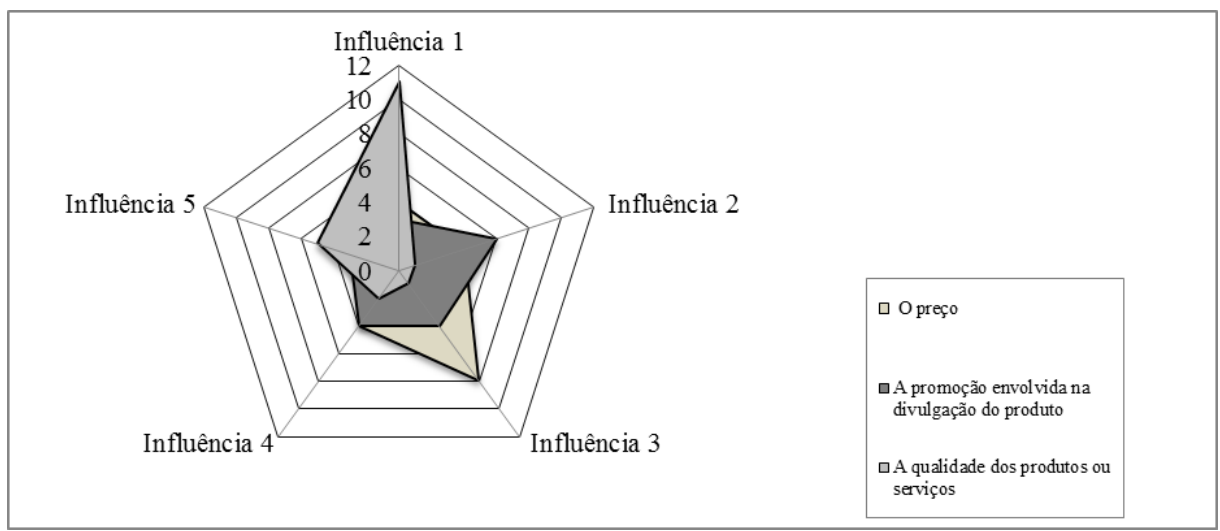

Gráfico 1. Influência dos fatores preço, promoção e qualidade. Fonte: Grupo de Foco.

No Gráfico 2, de acordo com a opinião dos respondestes, o fator inovação se reverte em posição de destaque, com um quantitativo de cinco das vinte opiniões. Permite se afirmar que o consumidor sempre está à procura de algo inovador que o satisfaça nas suas necessidades mais intimas. Assim, para satisfazer estas carências, os gestores nas organizações buscam obter vantagem competitiva assegurando posição de liderança na base dos argumentos tratados por Moreira (2007); este autor indica o incremento de inovação através de novos produtos e novos processos. Por isso é que a inovação em marketing é um ponto estratégico na decisão organizacional.

Enseja o comportamento de fidelização do cliente mediante práticas solidárias pela sustentabilidade, focalizando os seus produtos, o planejamento do preço, a distribuição e divulgação, bem como toda uma série de medidas que permita satisfazer com reponsabilidade socioambiental, os desejos do consumidor associado aos objetivos da organização. 


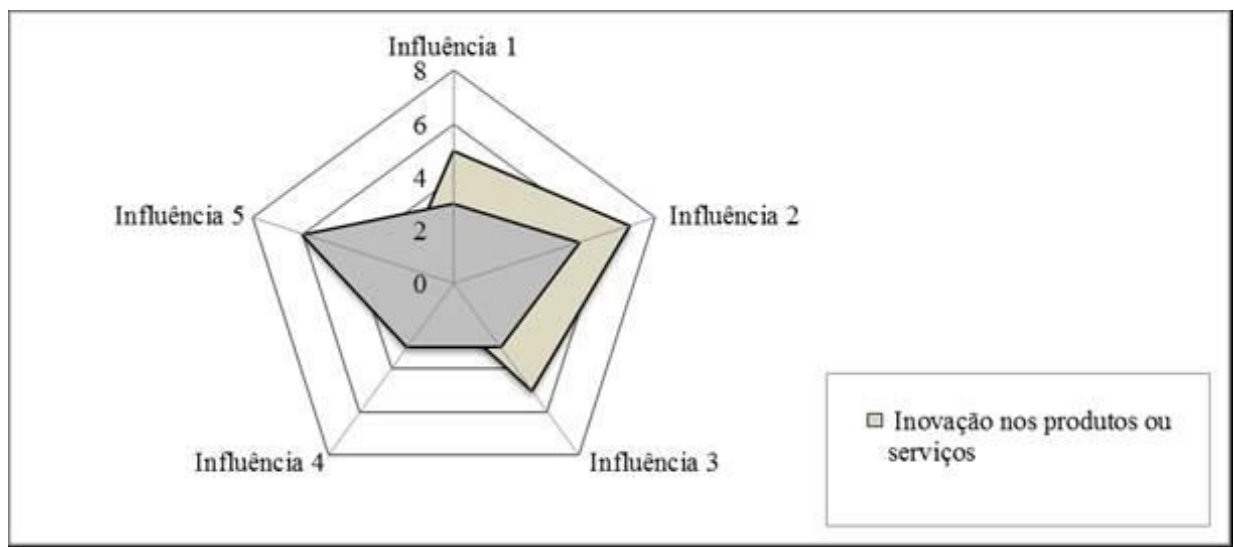

Gráfico 2. Influência de fatores inovação e responsabilidade social. Fonte: Grupo de Foco.

Depois de analisados os Gráficos 1 e 2, conclui-se que a qualidade e inovação nos produtos e serviços destacam-se com excelência quanto á influência na aquisição de produtos ou serviços. O consumidor não está tão preocupado com o valor do produto e sim com a qualidade e inovação que estes produtos apresentam. Este resultado induz nas organizações as estratégias para a qualidade e inovação de produtos, enquanto reforça a existência de um setor de pesquisa e desenvolvimento.

Avaliando a percepção dos atores sociais consultados sobre as variáveis ambientais contidas no Gráfico 3, se percebe que doze dos vinte respondentes do Grupo de Foco opinaram sobre a força da variável ambiental na concorrência, o que indica a sua influência na decisão organizacional na escolha dos processos de marketing. Este resultado está em conformidade ao que discorre Porter (1989) em sua teoria sobre cenários competitivos; este autor afirma que as organizações podem se defender e até influenciar essas forças favoráveis, impulsionando as decisões sobre produtos ou serviços. Neste panorama competitivo se destaca como uma força impulsionadora direta da concorrência, ensejando o planejamento de estratégias concernentes ao ambiente de marketing. Por exemplo, as organizações podem vir a modificar suas estratégias e diversificar produtos, e desta forma atingirem metas diversificadas. Em face desta diversificação os consumidores podem escolher entre qual produto adquirir, se sobressaindo no mercado quem busca qualificação nos produtos que ofertam. 


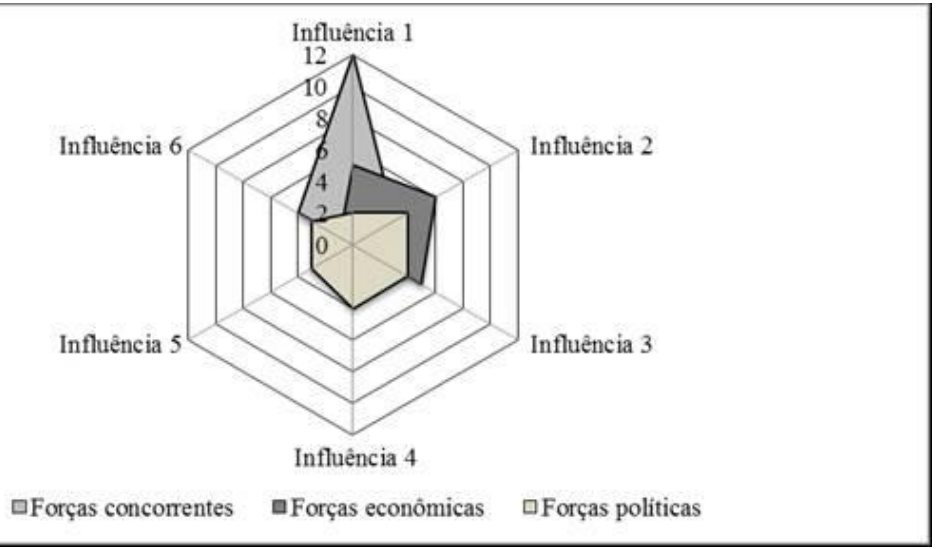

Gráfico 3. Influência das forças dos concorrentes, econômicas e politicas no marketing organizacional. Fonte: Grupo de Foco.

No Gráfico 4 consta a comparação dos resultados obtidos da percepção dos agentes do Grupo de Foco sobre as variáveis ambientais. Segundo os respondentes do Grupo de Foco, as forças tecnológicas influenciam sete das vinte opiniões de cada agente; essa tendência de crescimento da tecnologia está inserida na cultura de todas as organizações. As teorias tratadas neste estudo permitem ressaltar que a estrutura produtiva de cada organização depende de um tipo de tecnologia diferente, além de interferir no processo produtivo. Portanto a tecnologia influencia todas as áreas de uma organização, pois é um dos condutores de informação.

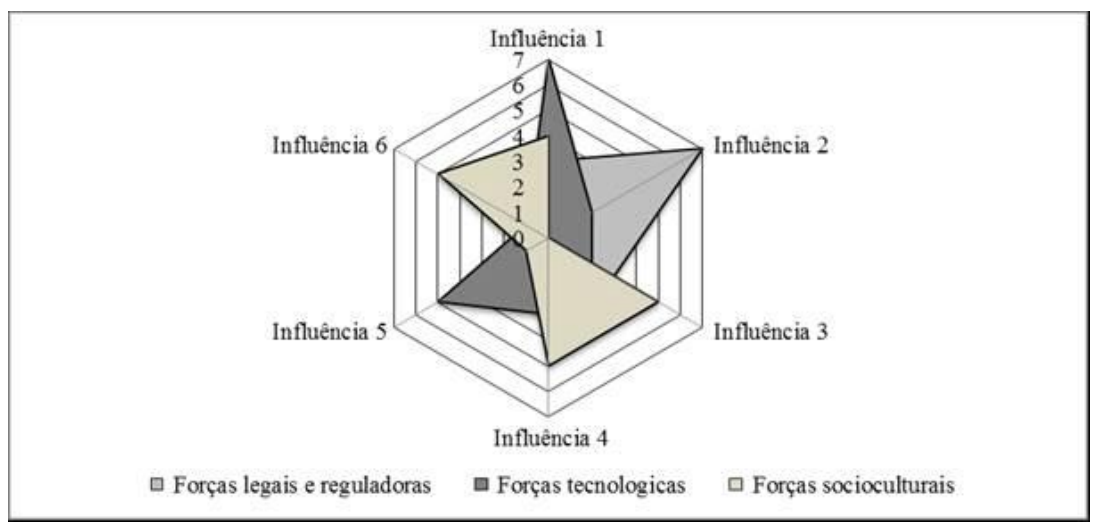

Gráfico 4. Influência das forças legais, tecnológicas e socioculturais no marketing organizacional. Fonte: Grupo de Foco. 
No que concerne às forças legais e regulamentadoras, três dos vinte respondentes acreditam que as leis e regulamentos influenciam, mas com pouca expressividade, porque muitas empresas ainda conseguem burlar essas leis e atuarem ilegalmente. Mesmo em face deste resultado, o correto para as empresas seria manter uma postura responsável. A conclusão que se chega diante dessas forças ambientais são que todas estão interligadas; entretanto uma não pode agir em detrimento da outra, visto que todas têm suas vantagens e desvantagens. Esta é uma via que segue desde os objetivos da organização, se adapta a essas forças criando oportunidades, e vantagens para obterem competitividade no mercado.

A análise sobre a tendência no desempenho organizacional mediante a aplicação da ferramenta do Marketing Verde é demonstrada no Gráfico 5 a seguir. A percepção dos agentes quanto à utilização do Marketing Verde pelas organizações teve um quantitativo de doze dos vinte respondentes. Foi abordado sobre o impulso nas organizações em face da propagação de informações midiáticas, por grupos defensores da natureza, sobre a existência destes posicionamentos nas ocorrências, e quanto a danos causados pelas organizações ao meio ambiente. Este posicionamento permite perceber a disposição na organização para a sustentabilidade, e ainda a sua responsabilidade social; indica à longo prazo o sucesso em cenários ambientalmente corretos.

Este resultado permite afirmar que o consumidor ainda desconfia das intenções em algumas organizações quanto à aquisição deste tipo de estratégia; talvez porque as informações ou a falta de clareza na divulgação e nos procedimentos utilizados estejam sendo processadas de forma a incutir no consumidor esta desconfiança. Para muitos consumidores ou clientes de grandes organizações ou marcas renomadas, os empreedimentos estão fazendo sua parte. Não poderia ser diferente porque, em decorrência da amplitude dos negócios do empreendimento, possivel será a proliferação de detritos industriais ou do consumo dos recursos naturais, estes que tornam a desconfiança procedente.

É prudente afirmar que o Marketing Verde utilizado em organizações é relevante e necessário, tanto para o consumidor quanto para a organização que o desenvolve. Diferentes opiniões se fazem necessárias, pois provoca enquadramento pela sustentabilidade nas organizações, enquanto envolverá a sociedade mediante diferentes opiniões, resultando compromisso coletivo, parcerias com órgãos governamentais em questões ambientais divulgadas, implicando no sinérgico sucesso do marketing verde na sociedade. 


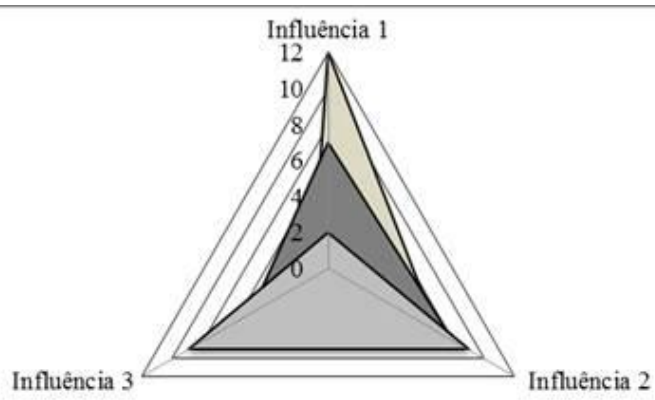

口Estão seguindo as novas tendências impulsionadas pelo mercado

口Estão utilizando os selos verdes somente para ganhar vantagem competitiva

口Estão preocupadas de fato com as questões sociais envolvidas na decisão de implantar o Marketing Verde

Gráfico 5. Percepção sobre as organizações que utilizam o Marketing Verde. Fonte: Grupo de Foco.

Foram levantados dados sobre o Marketing Verde como elemento de inovação do Marketing. Aqui $60 \%$ dos agentes do Grupo de Foco opinaram como relevante para as organizações, como um diferencial para obter vantagem competitiva frente à concorrência. Pode atingir demandas diferenciadas de consumo como afirma Ottman (1994); este autor trata das questões ambientais na condição de sobrevivência para a humanidade. Conclui-se que os consumidores reconhecem a importância quanto às questões que circundam as inovações; principalmente quando se introduz novos produtos, serviços ou processos que contribuem com uma melhoria contínua para a sociedade. Para as opiniões sequenciais $25 \%$ dos respondentes do Grupo de Foco acredita que a organização deverá analisar a demanda que se pretende alcançar para então decidir pela inovação em produtos desta linha no mercado. Um percentual de $5 \%$ dos agentes acredita que esse tipo de produto é modismo; possivel deduzir que os produtos voltados para a preservação do meio ambiente, ou que estão ligados diretamente às causas sociais, como os produtos alimentícios específicos para certos tipos de consumidores, são de fato diferencial em termos de concorrência. Mas a minoria tem a percepção de que seja passageira tal tendência.

A Gráfico 6 tem a função de demonstrar a aplicabilidade do marketing verde como estratégia organizacional. Serve como base coerente com as teorias e resultados neste estudo. Este diagrama é baseado nos fluxos operacionais de uma organização com foco no nível estratégico. Tem seu início em um processo inserido na organização dinâmica repensada, agora como um sistema aberto, orgânico e 
dinâmico. Ali as estratégias precisam ser delimitadas sobre esta estrutura; utilizouse a força do meio ambiente como uma etapa de processo para a criação da ferramenta estratégica Marketing Verde, para alcance de competitividade. Focaliza a responsabilidade social, o resultando na satisfação do mercado e o almejado diferencial competitivo. As setas menores têm a funcionalidade de integração entre os processos; para finalizar o processo exigiu-se a eficiência na organização, porque todos os esforços organizacionais almejam a eficiência, o que resulta no sucesso de suas operações. A seta maior evidencia um círculo virtuoso, porque as organizações reagem à medida que novos acontecimentos vão surgindo, realimentando todo o processo, proporcionando resultado favorável para a organização.

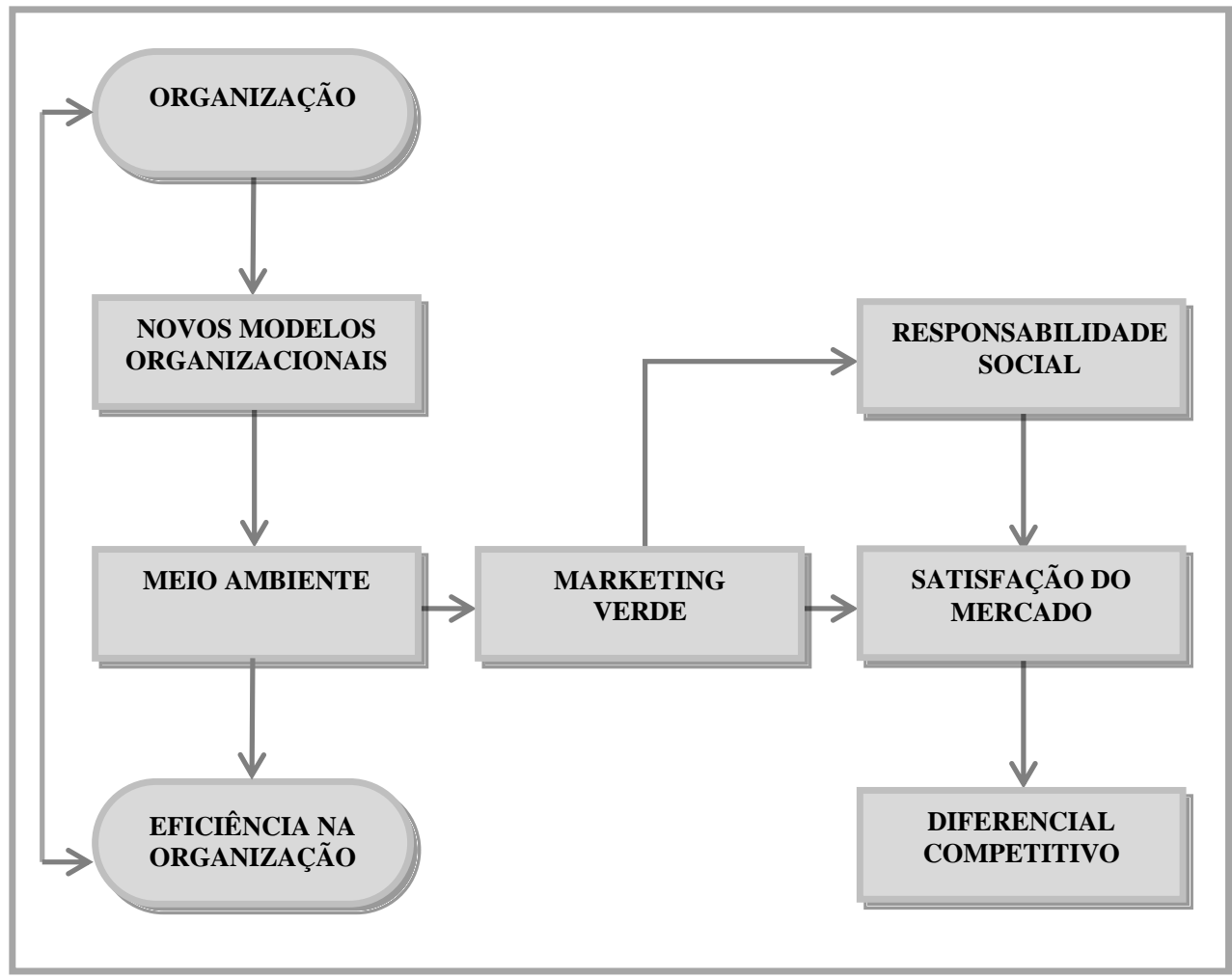

Gráfico 6. Demonstração da aplicação do marketing verde como estratégia organizacional. Fonte: Elaborado pelos autores. 
Em face de grandes mudanças no ambiente as organizações precisam adequar suas estratégias para um melhor desempenho dos recursos. Segue pelo desenvolvendo de consciência ecologicamente correta na cultura dessas organizações; resulta em prospecção de consumidores de seus produtos ou serviços, de modo a suprir seus objetivos em um ambiente dinâmico com foco na responsabilidade social. Cabe à organização ser a impulsionadora dessa conscientização, aprimorando sua base estrutural para alcançar expectativas de crescimento e através da disseminação de informações disponíveis ao consumidor sobre suas prerrogativas sustentáveis; o enquadramento da organização para um desempenho superior será alcançando com maior rapidez e consequentemente garantirá o sucesso em seus negócios.

\section{CONCLUSÃO E SUGESTÕES}

O Marketing Verde pode ser utilizado de diferentes formas, não apenas como promotor de vendas de produtos sustentáveis; vai muito além dessa tarefa de marketing e pode ser viável para as organizações que tenham características dinâmicas e querem inovar em seus negócios. As organizações podem inovar definindo um segmento no qual pretende atuar, e planejar desde a sua estrutura inicial até a divulgação do produto, focando na demanda que se pretende alcançar, como nos casos de negócios de ecoturismo. Se pode também inovar no que concerne à logística de movimentação dos produtos oferecidos pela organização. Os fornecedores têm que prestar um serviço de logística reversa, pois o descarte dos produtos por parte dos usuários pode ser aproveitado na maioria dos casos, realimentando a sua linha produtiva. Fazer parcerias com os lojistas e principais distribuidores dos seus produtos, como facilitadores e propagadores dessa ideia.

O Marketing Verde necessita de um aprimoramento para ser uma ferramenta estratégica de sucesso e para que seja comprovada sua eficácia. Embora alguns consumidores conheçam os empreendimentos com os quais mantem negócios, ainda desacreditam que essas organizações estejam fielmente envolvidas com as questões ambientais transmitidas à sociedade. A sugestão neste caso é que se divulgue não somente a finalidade desses produtos ou serviços, mas todo o processo de desenvolvimento destes produtos, pois as organizações têm que incutir na cultura da organização o desejo pela inovação, para então alcançar a atenção do consumidor.

As organizações devem fazer constantemente um benchmarking, porque precisam e necessitam comparar suas atividades com a dos concorrentes. Esta 
iniciativa possibilitará uma analise comparativa dos seus negócios, e também auxilia no desenvolvimento de novas estratégias com base no desempenho dos concorrentes. Aproveitar as oportunidades nesse tipo de técnica e agir preventivamente diante das ameaças do ambiente externo faz bem aos resultados.

\section{REFERÊNCIAS}

Cooper, D. R, e Schindler, P. S. (2004). Métodos de pesquisa em administração. Porto Alegre: Bookman.

Dias, R. (2007). Marketing ambiental: Ética, responsabilidade social e competitividade nos negócios. São Paulo: Atlas.

Kotler, P. (2000). Administração de marketing. São Paulo: Prentice Hall.

Moreira, D. A., e Queiroz, A. C. (2007). Inovação organizacional e tecnológica. São Paulo: Thomson Learning.

Ottman, J. A. (1994). Marketing verde: Desafios e oportunidades para a nova era do marketing. São Paulo: Makron Books.

Porter, M. E. (1989). Vantagem competitiva: Criando e sustentando um desempenho superior. Rio de Janeiro: Elsevier.

OECD. 1997. Manual de Oslo: Diretrizes para coleta e interpretação de dados sobre inovação. Brasil: OECD. Recuperado de: http://www.oei.es/salactsi/oslo2.pdf

Pride, W. M., e Ferrel, O. C. (2001). Marketing: conceitos e estratégias. Rio de Janeiro: LTC.

Tachizawa, T. (2006). Gestão ambiental e responsabilidade social corporativa: Estratégias de negócios focadas na realidade brasileira. São Paulo: Atlas.

Wood Jr, T. (2004). Mudança organizacional. São Paulo: Atlas. 